07

\title{
Акустическая эмиссия при взаимодействии скользящей дислокации с точечными препятствиями
}

\author{
(C) В.В. Благовещенский, И.Г. Панин ॠ \\ Костромской государственный университет, \\ Кострома, Россия \\ ๑ E-mail: igpanin@list.ru \\ (Поступила в Редакцию 22 декабря 2016 г. \\ В окончательной редакции 17 января 2017 г.)
}

С помощью математической модели движения скользящей дислокации вычисляется сигнал акустической эмиссии, сопровождающий процесс преодоления дефектов в кристалле. Дана оценка величин упругих напряжений в излучаемом сигнале. Установлено, что сигнал акустической эмиссии при срыве дислокации с дефекта значительно превосходит сигнал при торможении скользящей дислокации при встрече с дефектом. Эти сигналы имеют различную форму.

DOI: 10.21883/FTT.2017.08.44757.457

\section{1. Введение}

Явление акустической эмиссии происходит в кристаллических твердых телах при деформации, сопровождающейся образованием и эволюцией дислокационных ансамблей. Упругая энергия, излучаемая при этом, может регистрироваться диагностической аппаратурой, используемой для контроля над состоянием металлических конструкций $[1,2]$. Одним из возможных механизмов эмиссии является акустическое излучение, возникающее при работе источника Франка-Рида. Начальная стадия этого процесса, начинающаяся задолго до момента блокировки образующегося скопления обратными напряжениями, и сопровождающего его излучения моделировалась в работах Нацика и Чишко [3,4]. Теоретические расчеты акустической эмиссии при пластической деформации с коллективным движением дислокаций [5] показывают, что релаксация напряжений начинается с момента максимального значения акустического импульса, совпадающего по времени с максимальным значением напряжений в кристалле. В то же время полученная при этом кривая напряжения не совсем точно описывает реальный процесс деформирования ни с точки зрения опытных данных [6], ни с точки зрения результатов моделирования [7].

В $[8,9]$ экспериментально показано, что максимальной величины импульсы эмиссии достигают на пределе текучести.

В настоящей работе представлены данные акустической эмиссии при скольжении дислокации на площадке моделирования вплоть до выхода дислокации на поверхность кристалла.

\section{2. Модель}

Для исследования акустической эмиссии, сопровождающей скольжение дислокации через систему дефектов, была использована разработанная авторами ранее модель скольжения дислокации через систему дефектов [7]. Движение дислокации происходит в модельном образце, в котором расположены однородные дефекты (стопоры). Дислокационная линия, состоящая из отдельных связанных между собой дислокационных сегментов, опирающихся своими концами на стопоры, двигается от одного края площадки моделирования к другому (рис. 1). Каждый сегмент при движении изгибается, может столкнуться со встречными стопорами или сорваться с удерживающих его стопоров, при этом образуются новые сегменты.

Каждый шаг движения любого сегмента рассчитывается при помощи решения уравнения (1) $[3,10]$

$$
\begin{gathered}
p \frac{\partial U}{\partial t}-\frac{\partial^{2} U}{\partial \lambda^{2}}=S-\frac{1}{R(\lambda)}, \\
U(0, t)=U(L, t)=0 \forall t, \quad U(\lambda, 0)=0 \forall \lambda,
\end{gathered}
$$

где $p=B / G b^{2}, S=\sigma / G b, t-$ время, $G-$ модуль сдвига, $b$ - модуль вектора Бюргерса, $B$ - коэффициент динамической вязкости, $U-$ смещение точек дислокационного сегмента, $R(\lambda)$ - радиус кривизны сегмента в точке $\lambda, \sigma$ - величина внешнего напряжения, $\lambda$ - криволинейная координата вдоль сегмента, $L-$ длина сегмента. Уравнение (1) справедливо для таких смещений $U$ сегмента, что $U \gg L$, решается численно, методом сеток.

Таким образом, скольжение дислокаций будет прерывистым, существенно неравномерным, и сопровождается

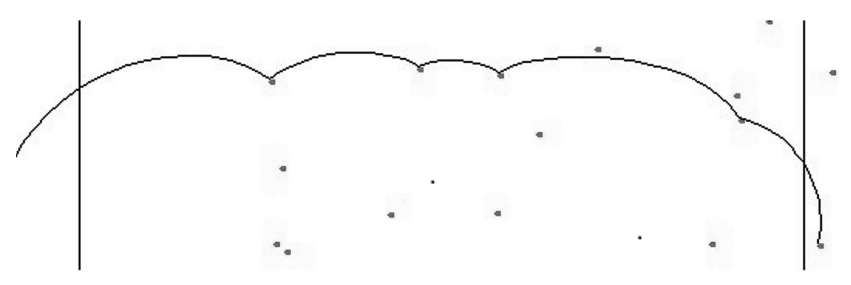

Рис. 1. Фрагмент работы модели движения дислокации. 
акустической эмиссией, которая возникает в моменты сталкивания дислокации с новым стопором или при срыве ее с одного из опорных стопоров.

\section{3. Результаты}

Акустическое излучение, сопровождающее процесс скольжения дислокации и выхода ее на поверхность, можно оценить формулой $[4,11]$ :

$$
\omega \approx G \frac{b}{r}\left(\frac{\rho b^{2} c}{l_{0} B}\right)^{2} \frac{d^{2} S}{d \tau^{2}},
$$

где $c-$ скорость звука, $\rho-$ плотность кристалла, $r$ - расстояние от источника до приемника сигнала, $\tau=t D / B l_{0}^{2}-$ безразмерное время, $D=$

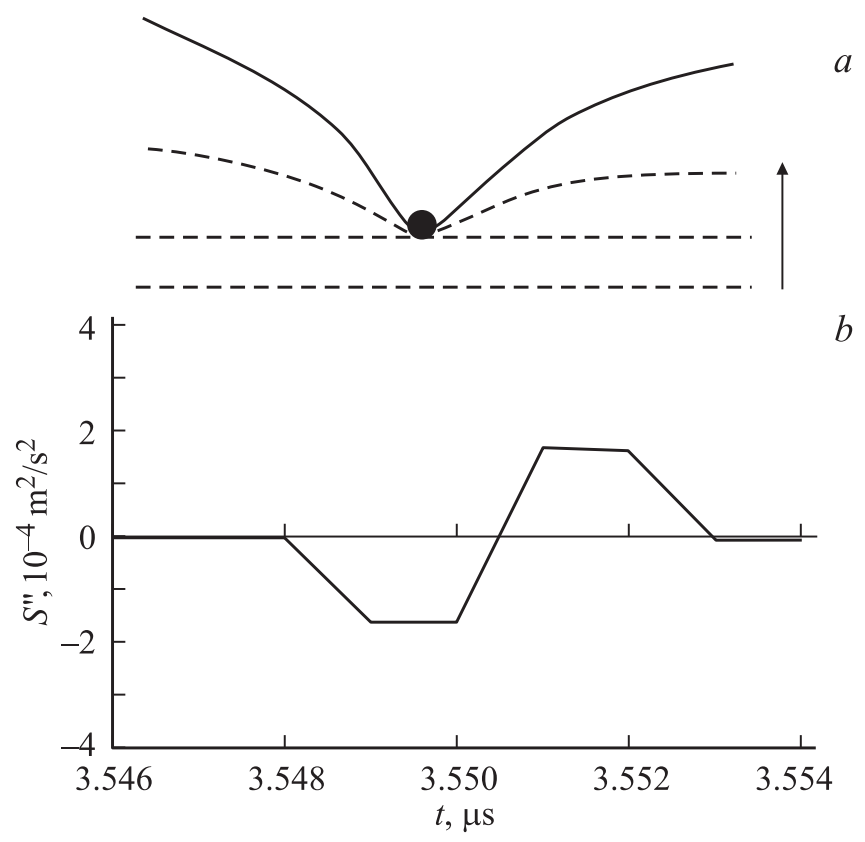

Рис. 2. Столкновение дислокации со стопором: a) схема столкновения, $b$ ) сигнал звуковой эмиссии.

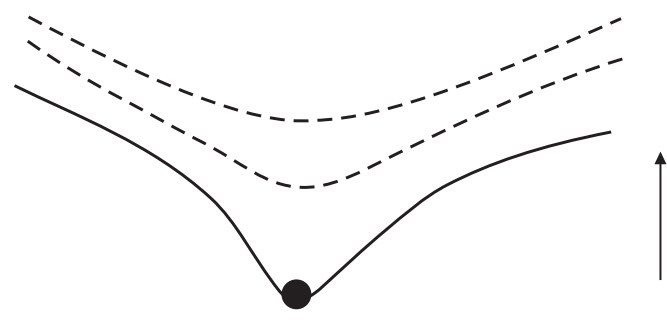

$a$

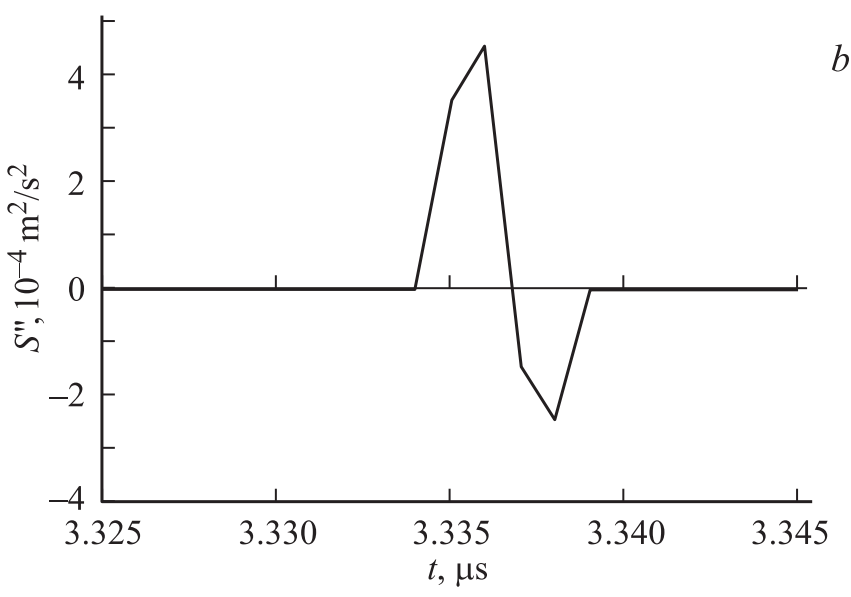

Рис. 3. Срыв дислокации со стопора: $a$ ) схема срыва, $b$ ) сигнал звуковой эмиссии.

$=\left(G b^{2} / 4 \pi\right) \ln \left(l_{0} / b\right)$. Из выражения (2) видно, что величина упругих напряжений излучения пропорциональна второй производной от заметаемой дислокацией площади, поэтому в исходную математическую модель было добавлено вычисление площади и ее второй производной для каждого момента времени.

Расчеты, проведенные на полученной модели, показали, что в моменты сталкивания со стопорами и срыва с них вторая производная заметаемой дислокацией площади скачкообразно меняет свое значение, в то время как при нормальном движении дислокации она меняется плавно. На рис. 2 и 3 представлены схематические изображения столкновения дислокации со стопором и

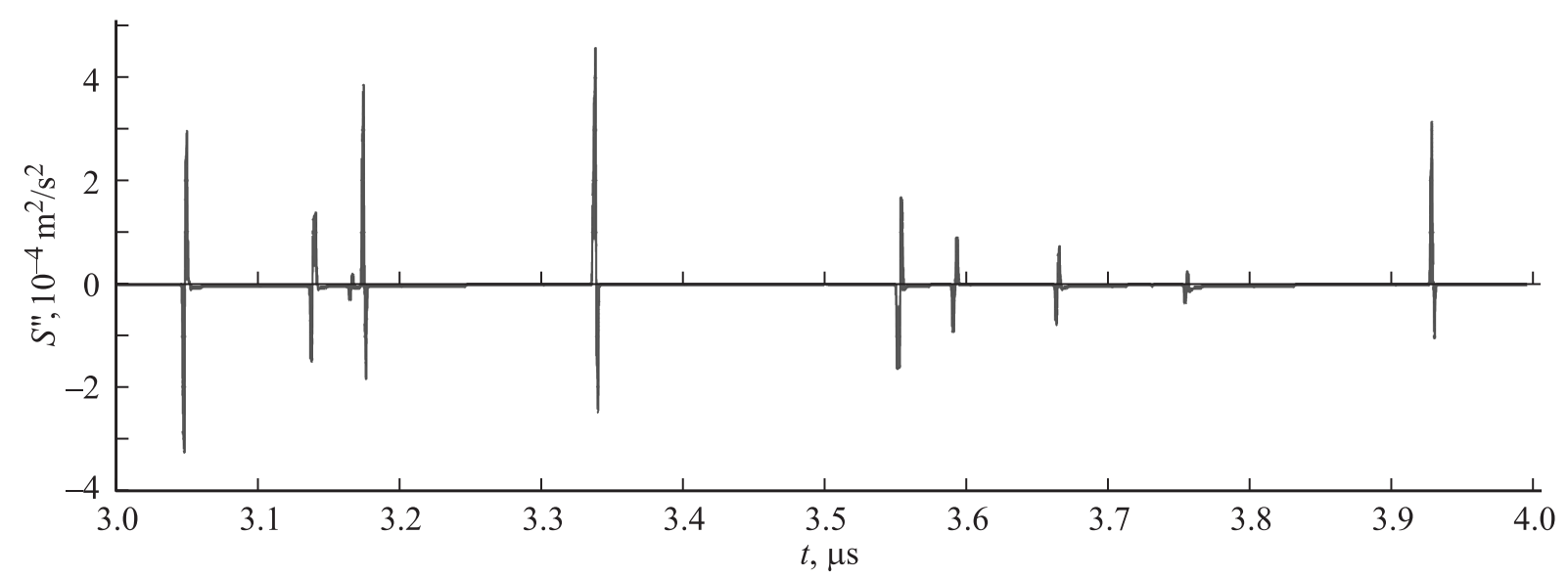

Pис. 4. Фрагмент последовательности сигналов акустической эмиссии. 
срыва с него, а также соответствующие им импульсы акустической эмиссии, полученные с помощью моделирования. Стрелками показаны направления движения дислокации.

В обоих случаях сигнал имеет форму двуполярного импульса. Но при сталкивании сначала имеем отрицательный „выброс“, затем положительный, а при срыве наоборот. Причем при срыве амплитуда импульса, как правило, на порядок больше, чем при сталкивании.

Необходимо заметить, что, хотя мощность всех дефектов и одинакова (угол срыва у всех дефектов равный), амплитуда импульсов на разных дефектах может отличаться, иногда значительно. На рис. 4 изображен сигнал акустической эмиссии при прохождении дислокации по площадке моделирования.

Пользуясь формулой (2), можно оценить упругие напряжения сигнала. Подставляя используемые параметры модели: $G=1.8 \cdot 10^{10} \mathrm{~Pa}, b=4 \cdot 10^{-10} \mathrm{~m}, \rho=5 \cdot 10^{3} \mathrm{~kg} / \mathrm{m}^{3}$, $r=10^{-2} \mathrm{~m}, \quad B=8 \cdot 10^{-4} \mathrm{~Pa} \cdot \mathrm{s}, \quad c=5 \cdot 10^{3} \mathrm{~m} / \mathrm{s}, \quad l_{0}=$ $=0.5 \cdot 10^{-6} \mathrm{~m}$, получим оценку для максимального импульса в серии (рис. 4) $\omega \sim 10^{2} \mathrm{~Pa}$.

\section{4. Заключение}

Амплитуда звукового импульса при срыве дислокации с дефекта значительно превышает амплитуду сигнала при торможении скользящей дислокации при встрече с дефектом, при этом соответствующие сигналы имеют существенно различную форму. Амплитуда положительного импульса, образовавшегося после срыва дислокации с дефекта, на порядок меньше величины импульса при срыве мощного дислокационного скопления, содержащего десяток дислокаций [12]. И может быть сравнима по величине с импульсом при срыве малодислокациоонного скопления.

\section{Список литературы}

[1] Т.В. Муравьев, Л.Б. Зуев. ЖТФ 78, 8, (2008). С. 135.

[2] N.V. Kamyshanchenko, I.S. Nikulin, E.S. Kungurtsev, M.S. Kungurtsev. Techn. Phys. Lett. 39, 5 (2013). P. 469.

[3] В.Д. Нацик, К.А, Чишко. ФТТ 17, 1 (1975). С. 342.

[4] В.Д. Нацик, К.А. Чишко. ФТТ 20, 7 (1978). С. 1933.

[5] J. Kumar, G. Ananthakrishna. Phys. Rev. Lett. 106, 10 (2011). P. 106001

[6] П.И. Полухин, Г.Я. Гун, А.М. Галкин. Сопротивление пластической деформации металлов и сплавов. Металлургия, M. (1983) $352 \mathrm{c}$.

[7] В.В. Благовещенский, И.Г. Панин. ФММ Т. 109. 3 (2010). C. 286.

[8] И.И. Папиров. East Eur. J. Phys. 2, 1 (2015). С. 63.

[9] Н.В. Камышанченко, И.Н. Кузьменко, М.Н. Роганин. Вестн. Тамбовского ун-та. Сер. Естеств. и техн. науки. 10, 2 (2005). C. 153.

[10] В.В. Благовещенский, И.Г. Панин. Изв. вузов. Матер. электрон. техники 2 (2007). С. 51.

[11] А.М. Косевич. Успехи физ. наук 84, 4 (1964) С. 579.

[12] Д.С. Андрианов, В.В. Благовещенский, И.Г. Панин. ЖТФ 86, 5 (2016). C. 124. 